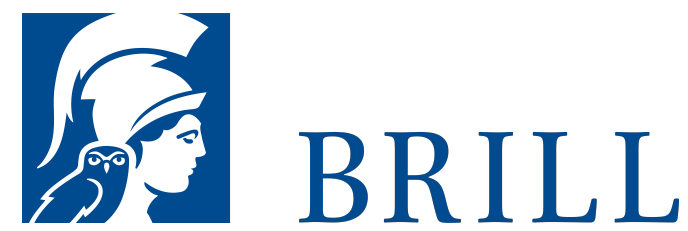

\title{
Drei Formen des Bewusstseins
}

Author: F. von Kutschera

Das Buch besteht aus fã $1 / 4$ nf Teilen, die ganz verschiedene Themen behandeln, inhaltlich aber durch den Gedanken unterschiedlicher Formen des Bewusstseins verbunden sind. Dieser Gedanke wird im ersten Teil entwickelt. Dort werden Struktur und Entfaltung intentionalen Bewusstseins dargestellt. Der Zusammenhang seiner beiden Pole, der subjektiv-geistigen und der objektiv-physischen RealitÃat, wird unter metaphysischen und erkenntnistheoretischen Aspekten erÃ rtert, es werden Grenzen intentionalen Erkennens aufgewiesen und es wird gezeigt, dass ebenso ein Vorstadium intentionalen Bewusstseins anzunehmen ist wie ein Bewusstsein, das die Grenzen intentionalen Denkens $\tilde{A}^{1} / 4$ berwindet. Der zweite Teil macht deutlich, dass ethischen Normen aus ethischen GrÃ $1 / 4$ nden enge Grenzen gesetzt sind. Im dritten Teil geht es um den ontologischen und erkenntnistheoretischen Status moralischer und Ã asthetischer Werttatsachen. Er stellt die Kontroverse zwischen Subjektivisten und Realisten dar: FÃ $1 / 4$ r Subjektivisten tragen wir durch unsere individuellen Interessen Wertunterschiede in eine an sich wertneutrale Welt hinein, wÃ ahrend fã $1 / 4 \mathrm{r}$ Realisten die Welt selbst Wertdimensionen hat. So einleuchtend der Wertrealismus auf den ersten Blick auch ist, so schwer IÃăsst er sich formulieren, denn bei der Frage der Erkennbarkeit objektiver Werte stoÃ Ÿen wir auf dieselben Schwierigkeiten wie im Fall der Erkennbarkeit...

See More

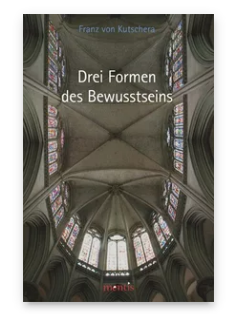

Pages: 231

Seiten

Language:

German

Subjects:

General,

Philosophy

Publisher: Brill | mentis

E-Book (PDF)

Released online:

O1 Nov 2014

ISBN: 978-3-

95743-992-5

List price

Paperback

Publication date:

O1 Dec 2014

ISBN: 978-3-

89785-495-6

List price 
For more information see brill.com

Order information: Order online at brill.com +44330 333 0049 | customerservices@brill.com Submission information: brill.com/authors

Titles published by Brill | Fink, Brill | mentis or Brill | Schöningh: +49(o)715413279216| brill@brocom.de 